\title{
Group selection harvesting supports diversity of forest specialist carabids
}

\author{
Bela Tóthmérész ${ }^{\ddagger}$, Tibor Magura ${ }^{\ddagger}$, Szabolcs Mizser ${ }^{\S}$, David D. Nagyl \\ ‡ University of Debrecen, Debrecen, Hungary \\ § MTA-DE Biodiversity and Ecosystem Services Research Group, Debrecen, Hungary \\ I MTA-DE Biodiversity and Ecosystem Services Research Group, P.O. Box 71, Debrecen, Hungary
}

Corresponding author: Bela Tóthmérész (tothmerb@gmail.com)

Received: 24 Jul 2019 | Published: 29 Jul 2019

Citation: Tóthmérész B, Magura T, Mizser S, D. Nagy D (2019) Group selection harvesting supports diversity of forest specialist carabids. ARPHA Conference Abstracts 2: e38499. https://doi.org/10.3897/aca.2.e38499

\begin{abstract}
Increased fragmentation and considerable environmental changes in native forests caused by the timber-oriented forest managements are threatening the biodiversity of forests. As a remediation, uneven-aged approach is recommended during forest management, because this is less intensive and could be less harmful than even-aged practices. We tested the effects of clear-cutting (as even-aged method) and group selection harvesting (as unevenaged method) on carabids in lowland oak forests. Pitfall traps and litter sifting were used during the study.

We found that the total number of species was significantly higher in the gaps harvested by group selection and in the clear-cut than in the mature forests (control area). The species richness of forest specialist species was significantly lower in the clear-cuts than in the other area. Our findings demonstrated that the conventional clear-cutting caused a decrease in the number of forest specialist species. Therefore, group selection method should be favoured during forest management to maintain diversity.
\end{abstract}

\section{Keywords}

clear-felling, diversity, forest practices, litter sifter, reforestation 


\section{Presenting author}

Bela Tóthmérész

\section{Presented at}

19thECM poster 